\title{
PROJETO NURC: HISTÓRICO
}

\section{Resumo:}

Nos últimos anos, os estudos sobre lingua falada desenvolveram-se muito nos meios acadêmicos brasileiros. Particularmente em São Paulo, esse desenvolvimento foi bastante influenciado pelo Projeto NURC. Este trabalho tem por objetivo estudar a origem do Projeto NURC, seus objetivos, suas diversas etapas e seus resultados práti$\cos$.

\section{Palavras-chave:}

Lingua falada; variedades lingüísticas; interação; conversaçño.

\section{O Projeto No Brasil}

A linguagem humana apresenta um feixe de variedades, a ponto de duas pessoas não falarem exatamente da mesma maneira a mesma língua, podendo, inciusive, uma única pessoa não falar da mesma forma em todos os momentos.

Sabemos, no entanto, que determinada variedade sobrepõe-se às demais por corresponder aos usos de determinado segmento da sociedade, isto é, aquele que desfruta de prestígio dentro da comunidade. A essa variedade chamamos norma culta.

Desde a década de 60, os lingüistas têm dado grande importância à questão das variedades lingüisticas. Nessa direção, nos últimos anos, os estudos sobre língua falada desenvolveram-se bastante nos meios acadêmicos brasileiros. Particularmente em São Paulo, o Projeto NURC foi responsável pelo avanço das pesquisas sobre língua falada. Passaremos a contar um pouco da história desse projeto que tem por objetivo documentar e descrever a nonna do português culto falado no Brasil.

Juan Lope Blanch, professor da Universidade Nacional Autônoma do Méxi$\mathrm{co}$, foi o autor da proposta de organização de um grande projeto coletivo, a fim de

\footnotetext{
* Mestre em Letras, professor de Língua Portuguesa na FFLCH/USP e pesquisador do Projeto NURC/SP.
} 
descrever a norma culta no espanhol falado. A proposta foi apresentada durante 0 II Simpósio do PILEI (Programa Interamericano de Lingüistica e Ensino de Idioma), em agosto de 1964, em Bloomington nos Estados Unidos da América. Assim nascia o "Proyeto de Estudio Coordinado de la Nomia Lingüística Culta de las Principales Ciudades de Iberoamérica y de la Península Ibérica".

Desde o inicio, já se pensava em estender o "Proyeto" às comunidades de língua portuguesa. Em janeiro de 1968, por ocasião do IV Simpósio do PILEI no México, o Prof. Nélson Rossi, da Universidade Federal da Bahia, apresentou o traballı "O Projeto de Estudo da Fala Culta e sua Execução no Dominio da Língua Portuguesa". Nesse estudo, o Prof. Nélson Rossi ressaltou que, diferente dos países de língua espanhola, no Brasil, o "Proyeto" não poderia limitar-se à capital do país nem ao Rio de Janeiro. Ele sugeriu que o "Proyeto" deveria abranger as cinco principais capitais com mais de um millão de habitantes: Recife, Salvador, Rio de Janeiro, São Paulo e Porto Alegre.

Em janeiro de 1969, durante o III Instituto Interamericano de Lingüistica, promovido em São Paulo pelo PILEI, o Prof. Nélson Rossi convocou uma reunião para relatar os entendimentos havidos com o PILEI para instalar o "Proyeto" no Brasil, esclarecendo, ainda, os objetivos e os procedimentos a serem tomados. Foi acertado que, para se instalar esse projeto, haveria necessidade de se escolherem os responsávcis pelo trabalho em cada una das cinco cidades. Cada responsável deveria recrutar pessoal necessário e levantar fundos. Assim nascia o Projeto NURC, o Projeto da Norma Urbana Culta das Principais Cidades Brasileiras.

Os coordenadores locais foram escollhidos:

$\begin{array}{ll}\text {-Recife: } & \text { Prof. José Brasileiro Villanova; } \\ \text {-Salvador: } & \text { Prof. Nélson Rossi; } \\ \text { - Rio de Janeiro: } & \text { Prof. Celso Cunha; } \\ \text {-São Paulo: } & \text { Profs. Isaac Nicolau Salum } \\ & \text { e Ataliba Teixeira de Castillo; } \\ \text {-Porto Alegre: } & \text { Prof. Albino de Bem Veiga. }\end{array}$

A partir de 1981, o Prof. Isaac Nicolau Salum foi substituído pelo Prof. Dino Preti na coordenação conjunta de São Paulo. Nas demais cidades, também houve mudança na coordenação. Por motivo de falecimento, en Recife, a Profa. Maria da Piedade Moreira de Sá substituiu o Prof. José Brasileiro Villanova; no Rio de Janeiro, a Profa Dinah Maria Insensee Callou substituiu o Prof. Celso Cunla. Por motivo de aposentadoria, o Prof. Nélson Rossi foi substituido pelas Profas. Jacyra Andrade Mota e Suzana Alice Marcellino Cardozo.

O projeto previa três etapas: gravações, transcrição e análise do corpus.

Inicialmente, o projeto previa 400 horas de gravação, selecionando-se 600 informantes ( 300 do sexo masculino e 300 do sexo feminino) com nivel superior de escolaridade, nascidos na cidade sob estudo ou residentes ai desde os cinco anos de idade, fillos de falantes nativos de língua portuguesa, de preferência nascidos na cidade sob pesquisa.

Os informantes foram distribuidos em três faixas etárias:

$\begin{array}{lll}-1^{\text {a }} \text { faixa etária: } & \text { de } 25 \text { a } 35 \text { anos de idade } & (30 \%) ; \\ -2^{\mathrm{a}} \text { faixa etária: } & \text { de } 36 \text { a } 55 \text { anos de idade } & (45 \%) ; \\ -3^{\mathrm{a}} \text { faixa etária: } & \text { mais de } 56 \text { anos de idade } & (25 \%) .\end{array}$

Quanto à natureza, as gravações foram divididas em quatro tipos:

$-1^{\circ}$. Gravações secretas de um diálogo espontâneo (GS): 40 horas (10\%); $-2^{\circ}$. Diálogo entre dois informantes (D2): 160 horas (40\%);

$-3^{\circ}$. Diálogo entre o informante e o documentador (DID): 160 horas (40\%); $-4^{\circ}$. Elocuções fonnais (EF): 40 horas (10\%).

Durante a X Reunião Nacional do Projeto NURC, realizada em 1977, no Rio de Janeiro, decidiu-se eliminar as gravações secretas. O momento político da década de 70 não permitia gravações desse tipo, podendo acarretar problemas de ordem política, difíceis de contornar. Assim, o corpus ficou reduzido para 300 horas.

Os assuntos abordados foram previamente selecionados e constam de um Guia-Questionário, abrangendo as seguintes áreas semânticas: corpo humano, alimentação, vestuário, casa, família, vida social; cidade, transportes e viagens; meios de comunicação e difusão, cinema, televisão, rádio, teatro; comércio exterior e política nacional; sindicatos e cooperativas; profissões e ofícios; dinheiro e finanças; instituições (ensino, igreja); meteorologia, tempo cronológico; terra, vegetais e agricultura, animais.

É evidente que, no Brasil, as próprias exigências do Projeto, somadas às dificuldades naturais de se fazer pesquisa e os obstáculos para se conseguirem os informantes adequados fizeram com que houvesse atraso na conclusão das gravações.

Em 1973, na VI Reunião Nacional, realizada em Porto Alegre, foram definidos os objetivos do Projeto NURC no Brasil:

1. Coletar material que possibilite o estudo da modalidade oral culta da lín gua portuguesa, em seus aspectos fonético, fonológico, morfossintático, sintático, lexical e estilístico.

2. Ajustar o ensino da lingua portuguesa a uma realidade lingüística concre ta, evitando a imposição indiscriminada de uma só nonna histórico-literária, por meio de um tratamento menos prescritivo e mais ajustado às diferenças lingüísticas e culturais do país. 
3. Superar o empirismo na aprendizagem da língua-padrão pelo estabeleci mento da norna culta real.

4. Basear o ensino em princípios metodológicos apoiados em dados lingüísticos cientificamente estabelecidos.

5. Conhecer as normas tradicionais que estão vivas e quais as superadas, a fim de não sobrecarregar o ensino com fatos lingüisticos inoperantes.

6. Corrigir distorções do esquema tradicional da educação brasileira, entra vado por uma orientação acadêmica e beletrista.

Tendo sido concluída a fase inicial de gravação, a situação do projeto no Brasil, em termos de acervo gravado, é a seguinte:

RECIFE:

363 entrevistas - 461 informantes - 307 horas e 20 minutos de gravação; SALVADOR:

357 entrevistas - 456 informantes - 304 horas de gravação;

RIO DE JANEIRO:

394 entrevistas - 493 informantes - 328 horas e 40 minutos de gravação; SÃOPAULO:

381 entrevistas - 474 informantes - 316 horas de gravação;

PORTOALEGRE

375 entrevistas - 472 informantes - 413 horas e 40 minutos de gravação.

Em 1985, durante a XIII reunião nacional do Projeto NURC, realizada em Campinas, decidiu-se que as cidades intercambiariam 18 entrevistas de seu acervo com as demais cidades. Esse acervo constituiu-se o que se convencionou chamar "corpus ininimo".

\section{ONURC/SP}

Duas equipes de documentação traballharam na constituição do arquivo sonoro do Projeto NURC/SP. A primeira, sob a direção da Prof Ada Natal Rodrigues, da Universidade de São Paulo, atuou de outubro de 1971 a abril de 1973. A equipe era integrada pelos seguintes pesquisadores: Berenice de Melo Freire, Esmeralda Vailati Negrão, Fernando Luiz Tarallo, Hiriko Chicuta, Maria Helena Vieira Lima e Maria Teresa Lopes Garcia da Silva. A segunda, sob a direção do prof. Dino Preti, da Universidade de São Paulo, atuou de novembro 1973 até a conclusão das gravações, em 1978. Era integrada pelos seguintes pesquisadores: Alzira C. S. Sene, Elza Gyun, Janice Yunes, José Iran Miguel, Luiz Antônio da Silva, Marlene Salles, Mônica de Barros Resende, Rosaura Correa da Silva, Rosinda de Castro Guerra e Sônia Abou Adal.
Até meados de 1984, a sala do Projeto ficava no CRUSP (Conjunto residencial da USP). Ali eram guardados todos os materiais, inclusive o arquivo sonoro. Nesse ano, houve a invasão do conjunto, mas, graças à dedicação do Prof. Dino Preti, todo o material foi salvo da destruição. Com a construção do prédio de Letras, foi destinada uma sala para o Projeto NURC.

Com a dupla coordenação em São Paulo - Prof. Dino Preti (USP) e Prof. Ataliba Teixeira de Castilho (UNICAMP) - o Projeto NURC/SP acabou tendo duas sedes, uma na Universidade de São Paulo e outra na UNICAMP.

A equipe de São Paulo logo se posicionou contra o modelo de análise da equipe hispânica, pois o modelo do "Guia-Questionário" se restringia aos aspectos da língua escrita. A partir dai, novos rumos foram sendo propostos para a análise dos dados lingüísticos do Projeto NURC.

Em 1984, houve na UNICAMP um seminário com o Prof. Luiz Antônio Marcuschi, da Universidade Federal de Pernambuco, recém chegado da Alemanha, onde havia estado em contato com o importante grupo de Freiburg. Nesse seminário, foram discutidas normas para a transcrição do corpus e novas estratégias e perspectivas de análise, considerando aspectos próprios da língua falada. A partir de 1985, o Prof. Dino Preti constituiu um grupo permanente de pesquisadores que passou a estudar textos, à luz da Análise da Conversação e sua aplicação ao material do Projeto NURC/SP.

Esse gnupo, com pequenas mudanças em seus integrantes, encarregou-se de transcrever o material do Projeto NURC/SP para publicação e posterior análise.

\section{RESULTADOS PRÁTICOS}

O grupo de pesquisadores dirigido pelo Prof. Dino Preti publicou duas séries, uma de amostra do corpus recolhido, outra de análises lingüísticas dos materiais:

CASTILHO, Ataliba Teixeira de e PRETI, Dino(1986) (Orgs.). A linguagem falada culta na cidade de São Paulo: materiais para seu estudo. São Paulo, T.A.Queirós, vol. I - Elocuções Formais (EF).

CASTILHO, Ataliba Teixeira de e PRETI, Dino(1987)(Orgs.). A linguagem falada culta na cidade de São Paulo: materiais para seu estudo. São Paulo, T.A.Queirós/ Fapesp, vol. Il - Diálogos entre dois informantes (D2).

PRETI, Dino e URBANO, Hudinilson(1988) (Orgs.). A linguagem falada culta na cidade de São Paulo: materiais para seu estudo. São Paulo, T.A.Queirós/Fapesp, vol. III - Entrevistas (DID).

Essas três publicações apresentam a transcrição de uma parte do material do NURC/SP. Esse material tem sido objeto de consultas de inúmeros pesquisadores, subsidiando publicações ensaísticas e constituindo corpus cuja análise vem sendo feita em monografias de mestrado e teses de doutorado. 
PRETI, Dino e URBANO, Hudinilson(1990) (Orgs.). A linguagem falada culta na cidade de São Paulo. São Paulo, T.A.Queirós/Fapesp, vol. IV - Estudos.

Essa obra é o quarto e último volume da série e contém estudos experimentais sobre o material colhido nas gravações do Projetỏ NURC/SP. A obra está dividida em duas partes. Na primeira, há três ensaios: "Procedimentos e funções da correção na conversação"; "O turno conversacional" e "A sobreposição de vozes numa perspectiva psicocultural e interacional". Na segunda, há um listórico do Projeto NURC no Brasil: "O português culto falado no Brasil - história do Projeto NURC/ BR".

\section{PRETI, Dino(1993) (Org.). Análise de textos orais. São Paujo, FFLCH/USP}

A obra acima já se encontra en $2^{a}$ edição e apresenta ensaios de vários especialistas. Segundo o Prof. Dino Preti, na apresentação da obra, os "pesquisadores da equipe do NURC/SP preocuparaun-se em escrever uma obra de iniciação à análise da língua oral, empregando um estilo acessivel a estudantes universitários (ou até préuniversitários), a professores secundários e usando apenas a nomenclatura técnica essencial. E, principalmente, partindo de textos falados reais, retirados do corpus do Projeto NURC/SP, usando, às vezes, textos escritos para comparação das teorias desenvolvidas."

Na obra, há dez ensaios. No primeiro, "Lingua falada e língua escrita", Ângela Cecilia Sousa Rodrigues apresenta algumas reflexões sobre problemas encontrados nas duas modalidades, falada e escrita. No segundo ensaio, "O tópico discursivo", Leonor Lopes Fávero mostra que a conversação "não é um enfileiramento aleatório de enunciados; ao contrário, ela é altamente estruturada e passível de uma análise formal". Em "O tumo conversacional", terceiro ensaio, Paulo de Tarso Galembeck propõe-se a "efetuar um estudo das formas de participação de cada interlocutor (turnos) e dos procedimentos pelos quais ocorre a troca de falantes." No quarto ensaio, "Marcadores conversacionais", Hudinilson Urbano tem por objetivo analisar os marcadores conversacionais, do ponto de vista formal, semântico, sintático e comunicativo-interacional. José Gaston Hilgert, autor do quinto ensaio - "Procedimentos de reformulação: a paráfrase", estuda a construção do texto, sua formação e planejamento e o fluxo da formulação. "Procedimentos de reformulação: a correção" é o sexto ensaio, escrito por Diana Luz Pessoa de Barros, cujo objetivo é estudar outro tipo de reformulação no texto oral, a correção. No sétimo ensaio, "O léxico na língua falada", Ieda Maria Alves discute o problema da definição dos vocábulos técnicos. Lygia Corrêa Dias, em seu ensaio - "A sintaxe na lingua falada", parte das definições de frase, oração e periodo e, em seguida, estabelece um paralelo entre $o$ que ocorre na lingua falada e na lingua escrita. "O processo interacional", nono ensaio, escrito por Beth Brait, apresenta um estudo sobre as estratégias utilizadas por falantes em contextos de interação verbal. Dino Preti, autor do último ensaio, estuda a elaboração do diálogo literário, procurando fazer um levantamento das marcas da oralidade no processo escrito literário. No final da obra, a fim de facilitar o trabalho do leitor, há um "Glossário", elaborado por Marli Quadros Leite e Rosane Malusá Gonçalves Peruchi.

Em 1987, durante o II Encontro da Associação Nacional de Pós-Graduação em Letras e Lingüística (ANPOLL), realizado na Universidade Federal do Rio de Janeiro, o Prof. Ataliba Teixeira de Castilho apresentou o "Projeto de Gramática do Português Falado". Segundo ele, o objetivo é a preparação de uma gramática referencial da variante culta do português falado no Brasil. Integram esse projeto mais de cinqüenta pesquisadores do Brasil, vinculados a universidades públicas e privadas, muitos deles integrantes do Projeto NURC. Embora o "Projeto de Gramática do Português Falado" não esteja vinculado ao Projeto NURC, o material de análise da "Gramática" é, essencialmente, o material do "corpus mínimo" do NURC.

Após várias reuniōes, foram feitas três publicações, sendo que o quarto e o quinto volumes já estão no prelo e o sexto, em organização. Os volumes já publicados são estes:

CASTILHO, Ataliba Teixeira de (Org.) (1990). Gramática do português falado. Campinas, Unicamp/Fapesp, vol. I - A Ordem.

ILARI, Rodolfo (Org.) (1992). Gramática do português falado. Campinas, Unicaınp, vol. II - Niveis de Análise Lingüística.

CASTILHO, Ataliba Teixeira de (Org.) (1993). Gramática do português falado. Campinas, Unicamp/Fapesp, vol. III - As Abordagens.

Aléın dessas publicações, houve outras motivadas pelo Projeto NURC. A equipe do Rio de Janeiro e de Salvador já prepararam suas publicações. As equipes de Recife e de Porto Alegre estão em fase de publicação:

CALLOU, Dinah (Org.) (1991). A linguagem falada culta na cidade do Rio de Janeiro: materiais para seu estudo. Rio de Janeiro, UFRJ/Faculdade de letras, vol. I - Elocuções Formais (EF).

CALLOU, Dinah e LOPES, Célia Regina (Orgs.) (1993). A linguagem falada culta na cidade do Rio de Janeiro: materiais para seu estudo. Rio de Janeiro, UFRJ/ CAPES, vol. II - Diálogos entre informante e documentador (DID).

MOTA, Jacyra e ROLLEMBERG, Vera (Orgs.) (1994). A linguagem falada culta na cidade de Salvador: materiais para seu estudo. Salvador, Instituto de Letras da UFBA, vol. I - Diálogos entre dois informantes (DID).

Embora não integre o Projeto NURC, o projeto LINGUAGEM DOS IDOSOS, 
desenvolvido pelo Prof. Dino Preti, utiliza material do NURC e é fruto das pesquist realizadas pela equipe do NURC/SP. Desse projeto, resultou a publicação:

PRETI, Dino (1991). A linguagem dos idosos. São Paulo, Contextò.

\section{Abstract:}

Over the last few years, a lot of studies on spoken language have been developed in the Brazilian academics circles. Especially in Sâo Paulo, being the Projeto NURC the major instrument for generating such studies. The aim of this paper is to study the origin of the Projeto NURC, its goals, its different stages and its practical results.

\section{Keywords:}

Spoken language; interaction; conversation.

\section{POESIA DE MANUEL BANDEIRA : LINGUAGEM E ESTILO}

\author{
Projeto: O Discurso da Poesia Modernista \\ Grupo de Iniciação Científica \\ Orientadora: Profa. Dra. Norma Seltzer Goldstein
}

Ana Elvira Luciano Gebara*e Mônica Simões Francisco de Sales**

O trabalho de análise e interpretação não visa somente a entender um texto literário mas também a ressaitar a sua importância. $O$ texto, traduzindo sentimentos, opiniões, apelos e emoções, é também um instrumento de representação da realidade segundo determinada visão de mundo. A literatura, por conseguinte, como diz Antonio Candido, é "um sistema simbólico, por meio do qual as veleidades mais profundas do individuo se transformam em elementos de contacto entre homens, e de interpretação das diferentes esferas da realidade"l Daí a necessidade de se realizar um tipo de pesquisa que possibilite um aprofundamento das bases teóricas dos estudos de estilística junto aos alunos de Graduação.

Há cerca de quatro anos, vem-se desenvolvendo um trabalho de Iniciação Cientifica com esse carater. Orientado pela Profa. Dra. Norma Seltzer Goldstein e seguindo o modelo proposto em seu livro Do Penumbrismo ao Modernismo : O Primeiro Bandeira e outros poetas significativos (Ática, 1983), formou-se um grupo para estudar a poesia de Manuel Bandeira, sua linguagem e estilo. $O$ modelo metodológico adotado se baseia na seleção de traços estilísticos significativos - de acordo com a freqüência em que aparecem enı poemas de determinado livro - os quais servem de critério para escolha de poemas a serem analisados.

O trabalho desenvolvido pela orientadora enfocava os três primeiros livros do autor: Cinza das Horas, Carnaval, Ritmo Dissoluto. Cada um dos componentes do grupo ficou responsável por um dos livros seguintes a partir de Libertinagem.

Em 1991, iniciamos a primeira etapa do traballı, discussão de textos teóri$\cos$. Em reuniões quinzenais, líamos e debatíamos textos correspondentes a quatro áreas determinadas pelo grupo, de acordo com a linha da pesquisa. Foram selecio-

* Licenciadas em Letras e especialista em Tradução pela USP. Mestranda na mesma universidade. ** Licenciada em Letras pela Universidade de São Paulo.

1 CANDIDO, 1959. Formaçĩo da Literatura Brasileira. Vol. 1. São Paulo: Livraria Martins Editora, p. 17. 